\title{
Gambaran Kepuasan Pasien terhadap Pelayanan Klinik Perioperatif Terintegrasi di RSUP Prof. Dr. R. D. Kandou
}

\author{
${ }^{1}$ Muliana E. Datu \\ ${ }^{2}$ Lucky T. Kumaat \\ ${ }^{2}$ Barry I. Kambey
}

\author{
${ }^{1}$ Program Studi Pendidikan Dokter Fakultas Kedokteran Universitas Sam Ratulangi Manado \\ ${ }^{2}$ Bagian Anestesi dan Terapi Intensif Fakultas Kedokteran \\ Universitas Sam Ratulangi Manado \\ Email: mauliana.datu@gmail.com
}

\begin{abstract}
Satisfaction is closely related with expected service and reality of the service available at the hospital. Satisfaction will be achieved if the performance is in line with the expectation of the patient. This study was aimed to obtain an overview of patient satisfaction towards the service provided by the Integrated Perioperative Clinic of Prof. Dr. R. D. Kandou Hospital. This was a descriptive study using questionnaire. Respondents were patients/families who received services at the clinic. The results showed a total of 100 respondents involved in this study, consisting of 30 females (30\%) and 70 males (70\%). Most respondents aged early to late adulthood numbering as many as 46 respondents (46\%). The majority of respondents numbering 44 respondents (44\%) had high school education level. Based on the analysis, high calculation results were obtained categorized as very good or very satisfied. In conclusion, the level of patient satisfaction towards the service provided by the Integrated Perioperative Clinic of Prof. R. D. Kandou Central Hospital based on the quality of service scale measuring direct evidence (tangibles), reliability, comprehension (responsiveness), assurance, and empathy was very high. It means that patients are very satisfied with the services provided by the clinic.
\end{abstract}

Keywords: patient satisfaction, quality of service, perioperative clinic

\begin{abstract}
Abstrak: Kepuasan sangat berkaitan dengan pelayanan yang diharapkan dan kenyataan pelayanan yang telah diberikan di rumah sakit. Kepuasan akan terpenuhi bila pelayanan yang diberikan dirasakan telah sesuai dengan harapan pasien. Penelitian ini bertujuan untuk mengetahui gambaran kepuasan pasien terhadap pelayanan klinik perioperatif terintegrasi di RSUP Prof Dr. R. D. Kandou. Jenis penelitian ialah deskriptif dengan menggunakan kuesioner. Responden penelitian ialah pasien yang mendapatkan pelayanan di klinik perioperatif. Hasil penelitian mendapatkan total 100 responden yang terdiri dari 30 orang perempuan (30\%) dan 70 orang laki-laki (70\%). Responden berusia dewasa awal dan dewasa akhir yang terbanyak yaitu 46 orang (46\%). Sebagian besar responden memiliki tingkat pendidikan SMA sebanyak 44 orang $(44 \%)$. Hasil analisis mendapatkan hasil perhitungan yang tinggi dan masuk dalam kategori sangat baik atau sangat puas. Simpulan penelitian ini ialah tingkat kepuasan pasien terhadap pelayanan klinik perioperatif terintegrasi di RSUP Prof. Dr. R. D. Kandou Manado berdasarkan skala kualitas pelayanan yaitu bukti langsung (tangibles), kehandalan (reliability), daya tangkap (responsiveness), jaminan (assurance), dan empati (empathy) sangat tinggi yang berarti pasien merasa sangat puas atas pelayanan yang diberikan oleh klinik perioperatif terintegrasi.
\end{abstract}

Kata kunci: kepuasan pasien, kualitas pelayanan, klinik perioperatif 
Kesehatan adalah keadaan sehat, baik secara fisik, mental, spiritual maupun sosial yang memungkinkan setiap masyarakat untuk hidup produktif secara sosial dan ekonomis. $^{1}$ Kesehatan juga merupakan suatu kebutuhan yang mendasar bagi setiap manusia, dan atas kebutuhan tersebut setiap manusia merasa perlu untuk menjaga kesehatan dan berhak mendapatkan pelayanan kesehatan yang aman, bermutu, dan terjangkau. Jaman sekarang ini, masyarakat semakin sadar dan mengharapkan pelayanan kesehatan yang lebih mementingkan kepuasan pasien dan juga dapat memenuhi kebutuhan dasar masyarakat. ${ }^{2}$

Rumah sakit adalah institusi pelayanan kesehatan yang menyelenggarakan pelayanan kesehatan perorangan secara paripurna. $^{3}$ Sebagai salah satu penyedia jasa kesehatan, rumah sakit dituntut untuk bisa bersaing dengan rumah sakit lain untuk memberikan pelayanan kepada pasien demi meningkatkan mutu dan juga mempertahankan standar pelayanan rumah sakit. ${ }^{4}$

Kualitas pelayanan merupakan suatu pendekatan dalam menjalankan usaha yang mencoba untuk memaksimalkan daya saing suatu organisasi melalui perbaikan atau peningkatan terus menerus dari suatu produk, tenaga kerja, proses, dan lingkungannya. Diperlukan strategi kerja yang berfokus pada pelanggan dalam hal ini pasien, jaminan kepuasan, kerjasama tim, dan pemberdayaan karyawan. ${ }^{5}$

Kepuasan sangat berkaitan dengan pelayanan yang diharapkan dan kenyataan pelayanan yang telah diberikan di rumah sakit. Kepuasan akan terpenuhi bila pelayanan yang diberikan dirasakan telah sesuai dengan harapan pasien. Namun, jika suatu rumah sakit memberikan pelayanan yang belum sesuai dengan harapannya maka pasien akan merasa tidak puas karena tidak sesuai dengan harapannya. Ketidakpuasan tersebut yang mendorong pasien untuk menggunakan jasa atau pelayanan rumah sakit lain dan pada akhirnya akan menurunkan mutu dan standar pelayanan dari rumah sakit tersebut.

Untuk menilai tingkat keberhasilan dalam memberikan pelayanan maka dibu- tuhkan survei kepuasan untuk memperoleh informasi mengenai kepuasan yang dirasakan oleh pasien. Oleh sebab itu, pengukuran kepuasan pasien perlu dilakukan secara berkala dan akurat agar supaya rumah sakit dapat mengetahui sejauh mana tingkat pelayanan yang sudah dilakukan.

Rumah Sakit Umum Pusat Prof. Dr. R. D. Kandou ialah rumah sakit pendidikan dan pusat rujukan kesehatan Provinsi Sulawesi Utara dan Indonesia Timur dan memiliki motto yaitu "Kepuasan pelanggan di atas segalanya" yang artinya rumah sakit selalu berfokus terhadap pelayanan dan meningkatkan mutu pelayanan yang berorientasi pada kepuasan pasien. ${ }^{6}$

Klinik perioperatif merupakan tempat untuk mengoptimalkan kondisi pasien yang akan dilakukan tindakan bedah. Pengoptimalan kondisi pasien akan mengurangi angka penundaan dan pembatalan tindakan operasi; juga akan mengurangi angka morbiditas dan mortalitas perioperatif. Manfaat yang diberikan dengan adanya klinik perioperatif ini ialah mengurangi waktu tunggu pasien untuk dilakukan tindakan dan juga mengurangi pemeriksaan penunjang atau konsultasi sub-spesialis yang tidak terlalu dibutuhkan. Dengan mengurangi hal tersebut maka akan berdampak pada ekonomi pasien yaitu pasien maupun keluarga pasien tidak akan mengeluarkan uang lagi untuk biaya pemeriksaan yang tidak terlalu dibutuhkan dan dengan sendirinya akan berpengaruh pada kepuasan pasien tersebut.

Berdasarkan latar belakang ini maka penulis tertarik untuk mengetahui gambaran kepuasan pasien terhadap pelayanan klinik perioperatif terintegrasi di RSUP Prof Dr. R. D. Kandou.

\section{METODE PENELITIAN}

Penelitian ini dilaksanakan pada bulan Oktober-November 2019 di Klinik Perioperatif Terintegrasi RSUP Prof. Dr. R. D. Kandou Manado. Jenis penelitian ialah deskriptif dengan jumlah responden sebanyak 100 orang, terdiri dari pasien dan keluarga pasien yang telah mendapatkan pelayanan. Instrumen penelitian ialah 
kuesioner yang divalidasi dengan software SPSS 16.0 for windows. Analisis data dilakukan terhadap data demografi dan data kuesioner yang diperoleh.

\section{HASIL PENELITIAN}

Pengujian validitas dilakukan terhadap 10 responden. Uji validitas dilakukan untuk menghitung korelasi antara masing-masing pernyataan dengan skor total. Nilai korelasi yang dihitung dinyatakan sah bila $r>0,361$. Hasil pengujian validitas menunjukkan bahwa semua pertanyaan dapat dijadikan kuesioner karena hasil uji validitas tersebut melebih 0,361 .

Pada penelitian ini digunakan instrumen penelitian berupa kuesioner yang dibagikan kepada pasien maupun keluarga pasien yang telah mendapatkan pelayanan. Jumlah responden yang berpartisipasi sebanyak 105 orang tetapi data responden yang diambil dan diolah hanya berjumlah 100 orang karena 5 responden lainnya berada di kriteria eksklusi. Responden yang berpartisipasi terdiri dari 30 orang perempuan $(30 \%)$ dan 70 orang laki-laki (70\%). Responden berusia dewasa awal dan dewasa akhir merupakan jumlah terbesar yaitu sebanyak 46 orang (46\%). Sebagian besar responden memiliki tingkat pendidikan SMA sebanyak 44 orang responden (44\%). Penilaian dilakukan dengan analisis menggunakan rumus index dan diinterpretasikan pada skor berdasarkan interval.

Tabel 1 memperlihatkan bahwa sebagian besar responden yang berpartisipasi dalam penelitian ini memberikab penilaian yang baik dan merasa puas terhadap dimensi bukti langsung; dalam hal ini ialah kebersihan dan kenyamanan klinik, juga tenaga kesehatan yang mampu menunjukkan kemampuannya dalam melakukan pelayanan.

Tabel 2 memperlihatkan bahwa sebagian besar responden yang menerima pelayanan memberi penilaian baik dan merasa sangat puas.

Tabel 3 memperlihatkan bahwa sebagian besar responden memberi penilaian baik tetapi terdapat beberapa responden yang memberikan penilaian yang raguragu.

Tabel 4 memperlihatkan bahwa responden yang memberi penilaian baik lebih besar dari pada responden yang memberi penilaian yang tidak baik, dan responden yang memberikan penilaian baik merasa puas dengan pelayanan dari dimensi jaminan.

Tabel 5 memperlihatkan bahwa sebagian besar responden memberi penilaian baik dan merasa puas terhadap pelayanan dari dimensi empati.

Tabel 1. Analisis dimensi bukti langsung

\begin{tabular}{lc}
\hline \multicolumn{1}{c}{ Butir Pertanyaan } & Rumus Index \\
\hline Ruang tunggu klinik sudah bersih dan nyaman & $90,4 \%$ \\
Tenaga kesehatan dapat menunjukkan kemampuannya dalam & $91,4 \%$ \\
melakukan pelayanan & \\
\hline
\end{tabular}

Tabel 2. Analisis dimensi kehandalan

\begin{tabular}{lc}
\hline \multicolumn{1}{c}{ Butir Pertanyaan } & Rumus Index \\
\hline Petugas dapat memberikan penjelasan yang mudah dimengerti & $91 \%$ \\
Tenaga kesehatan handal dalam melakukan tindakan & $89,6 \%$ \\
\hline
\end{tabular}

Tabel 3. Analisis dimensi daya tanggap

\begin{tabular}{lc}
\hline \multicolumn{1}{c}{ Butir Pertanyaan } & Rumus Index \\
\hline Petugas dapat melakukan pelayanan dengan cepat & $89,8 \%$ \\
Petugas dapat melakukan pelayanan dengan tanggap & $89,2 \%$ \\
\hline
\end{tabular}


Tabel 4. Analisis dimensi jaminan

\begin{tabular}{lc}
\hline \multicolumn{1}{c}{ Butir Pertanyaan } & Rumus Index \\
\hline $\begin{array}{l}\text { Petugas dapat menjamin keamanan dan kepercayaan terhadap } \\
\text { pelayanan }\end{array}$ & $90,2 \%$ \\
$\begin{array}{l}\text { Petugas kesehatan memberikan kesempatan pada pasien untuk } \\
\text { bertanya }\end{array}$ & $90,6 \%$ \\
\hline
\end{tabular}

Tabel 5. Analisis dimensi empati

\begin{tabular}{lc}
\hline \multicolumn{1}{c}{ Butir Pertanyaan } & Rumus Index \\
\hline $\begin{array}{l}\text { Petugas memberikan pelayanan dengan sopan dan ramah } \\
\text { Petugas kesehatan memberi pelayanan terhadap pasien tanpa } \\
\text { pilih kasih }\end{array}$ & $90,6 \%$ \\
\hline
\end{tabular}

\section{BAHASAN}

Hasil penelitian ini mendapatkan bahwa sebagian besar responden yang berpartisipasi dalam penelitian ini memberi penilaian yang baik dan merasa puas terhadap dimensi bukti langsung; dalam hal ini ialah kebersihan dan kenyamanan dari klinik dan juga tenaga kesehatan yang mampu menunjukkan kemampuannya dalam melakukan pelayanan (Tabel 1). Bukti fisik dapat memberi gambaran tentang kualitas pelayanan rumah sakit maupun klinik dan dalam beberapa hal akan sangat memengaruhi pasien dalam menilai kualitas pelayanan tersebut. ${ }^{7}$ Pada penelitian yang dilakukan oleh Lumintang ${ }^{8}$ di RSUP Prof. Dr. R. D. Kandou Manado didapatkan bahwa kondisi lingkungan fisik merupakan faktor yang berpengaruh secara bermakna terhadap kepuasan pasien. Demikian juga penelitian yang dilakukan oleh Kambong et $\mathrm{al}^{9}$ melaporkan adanya hubungan antara pelayanan perawat dalam dimensi bukti fisik, kehandalan, jaminan, kepedulian dengan kepuasan pasien.

Hasil penelitian ini mendapatkan bahwa sebagian besar responden yang menerima pelayanan memberi penilaian baik dan merasa sangat puas (Tabel 2). Hal ini menunjukkan bahwa kepuasan terhadap pelayanan klinik dari dimensi kehandalan ini sudah baik serta harus dipertahankan, dan jika memungkinkan pelayanan yang diberikan lebih ditingkatkan lagi. Hasil penelitian yang dilakukan oleh Hendrik ${ }^{10}$ menyatakan bahwa kehandalan memiliki pengaruh bermakna terhadap kepuasan pelanggan. Berdasarkan hal tersebut dapat dilihat bahwa kehandalan sangat memengaruhi penilaian yang akan diberikan oleh pasien maupun keluarga pasien.

Hasil penelitian ini mendapatkan bahwa sebagian besar responden memberi penilaian baik tetapi terdapat beberapa orang responden yang memberikan penilaian yang ragu-ragu (Tabel 3). Beberapa responden memberikan penilaian ragu-ragu pada jawaban pelayanan yang diberikan cepat dan tanggap. Hal ini menunjukkan bahwa penilaian responden tentang petugas memberi pelayanan yang cepat dan tanggap dapat ditingkatkan lagi. Umumnya pasien akan mengalami kesulitan saat melakukan pendaftaran untuk mendapatkan pelayanan di klinik sehingga pasien maupun keluarga pasien akan merasa tidak nyaman jika harus terlalu lama menunggu. Pada penelitian ini didapatkan bahwa sebagian besar responden merasa bahwa petugas di klinik sangat tanggap dan cepat dalam melakukan pelayanan, baik dalam memberikan penjelasan maupun membantu pasien yang kesulitan dengan proses pendaftaran. Namun masih terdapatnya kelompok pasien yang tidak puas berarti keseluruhan aspek tersebut belum optimal dan masih bisa ditingkatkan agar supaya tidak menimbulkan ketidakpuasan pada pasien maupun keluarga pasien. Badri et $\mathrm{al}^{11}$ mengemukakan bahwa daya tanggap merupakan salah satu dari 12 indikator yang selalu dimasukkan dalam berbagai penelitian 
yang berhubungan dengan mutu pelayanan. Hasil penelitian yang dilakukan oleh Mumu et $\mathrm{al}^{12}$ menyatakan bahwa terdapat hubungan antara daya tanggap dan kepuasan pasien.

Hasil penelitian ini mendapatkan bahwa responden yang memberi penilaian baik lebih banyak dari pada responden yang memberi penilaian tidak baik. Selain itu, responden yang memberikan penilaian baik merasa puas dengan pelayanan dari dimensi jaminan (Tabel 4). Hal ini menunjukkan bahwa pasien merasa aman dan percaya terhadap pelayanan yang diberikan oleh dokter maupun perawat dan juga merasa puas karena diberikan kesempatan untuk bertanya mengenai hal-hal yang tidak diketahui atau tidak dimengerti baik oleh pasien maupun keluarga pasien berkaitan dengan tindakan yang akan dilakukan atau instruksi yang diberikan oleh petugas. Jaminan dalam teori SERVQUAL merupakan pengetahuan, kemampuan, kesopanan, dan sifat dapat dipercaya yang dimiliki oleh petugas kesehatan klinik untuk membantu pasien. ${ }^{13}$ Semakin tinggi jaminan yang diperlihatkan oleh petugas maka akan semakin memengaruhi kepuasan pelanggan. Penelitian yang dilakukan oleh Hendrik $^{10}$ di Rumah Sakit Elim Kabupaten Toraja Utara menyatakan bahwa terdapat pengaruh bermakna antara jaminan terhadap kepuasan pelanggan.

Hasil penelitian ini mendapatkan bahwa sebagian besar responden memberi penilaian yang baik dan merasa puas terhadap pelayanan dari dimensi empati (Tabel 5). Hal ini sangat penting karena pasien dan keluarga pasien sangat mengharapkan agar dilayani dengan sopan dan ramah. Jika petugas memberikan pelayanan yang sebaliknya maka pasien akan merasa tidak nyaman yang akan berujung pada ketidakpuasan. Menurut Calisir et al ${ }^{14}$ ketidakpuasan mungkin merupakan hasil dari persepsi umum oleh karena meningkatnya jumlah pasien, beban kerja yang berat, dan pertimbangan kinerja maka petugas kesehatan tidak memberikan perhatian secara pribadi kepada pasien. Namun berdasarkan hasil yang didapat sebagian besar responden sangat puas dan merasa nyaman untuk datang ke klinik karena memperoleh pelayanan yang sopan dan ramah dari dokter maupun perawat yang bertugas di klinik. Responden juga merasa puas karena petugas kesehatan yang bertugas di klinik memberikan pelayanan kepada semua pasien tanpa pilih kasih atau tanpa melihat status dari pasien tersebut.

\section{SIMPULAN}

Berdasarkan hasil penelitian ini dapat disimpulkan bahwa tingkat kepuasan pasien terhadap pelayanan Klinik Perioperatif Terintegrasi RSUP Prof. Dr. R. D. Kandou Manado menurut skala kualitas pelayanan yaitu bukti langsung (tangibles), kehandalan (reliability), daya tanggap (responsiveness), jaminan (assurance), dan empati (empathy) sangat tinggi yang berarti pasien merasa sangat puas atas pelayanan yang diberikan oleh dokter dan perawat yang bertugas di Klinik Perioperatif Terintegrasi.

Bagi peneliti selanjutnya disarankan untuk menambah jumlah responden yang terlibat dalam penelitian ini. Diharapkan hasil penelitian ini menjadi bahan evaluasi untuk Klinik Perioperatif Terintegrasi dalam mempertahankan dan meningkatkan kualitas pelayanan yang diberikan, sebagai contoh ialah penambahan jumlah tempat duduk bagi pasien atau keluarga pasien yang datang di klinik perioperatif dan pemeliharaan kebersihan ruang tunggu dan ruang klinik. Selain itu, disarankan untuk menambahkan petugas kesehatan baik dokter dan perawat agar pelayanan dapat lebih baik lagi. Diharapkan Klinik Perioperatif Terintegrasi dapat meningkatkan kualitas dalam dimensi daya tanggap untuk meningkatkan kepuasan pasien dan melakukan pengukuran tingkat kepuasan secara berkala.

\section{DAFTAR PUSTAKA}

1. Republik Indonesia. Undang-undang No. 36 Tahun 2009 tentang Kesehatan. Jakarta, 2009.

2. Gultom JR. Analisis kepuasan pasien terhadap pelayanan rawat jalan di Poliklinik 
Rumah Sakit Azra tahun 2008 [Skripsi]. Jakarta: Universitas Indonesia; 2008.

3. Republik Indonesia. Undang-undang No. 44 Tahun 2009 tentang Rumah Sakit. Jakarta, 2009.

4. Hamid. Analisis tingkat kepuasan pasien rawat jalan di Rumah Sakit dr. H. Marzoeki Mahdi Bogor [Skripsi]. Bogor: Institut Pertanian Bogor; 2010.

5. Tjiptono F. Total Quality Management. Yogyakarta: Penerbit Andi, 2005.

6. RSUP Prof. Dr. R. D. Kandou. Tingkatkan terus pelayanan. 2018 Aug 8 [cited 2019 Aug 25]. Available from: https://www. rsupkandou.com/basic/read/807

7. Tjiptono F. Pemasaran Jasa - Prinsip. Penerapan, dan Penelitian. Yogyakarta: Penerbit Andi, 2014; p. 265-346.

8. Lumintang SS. Faktor-faktor yang berhubungan dengan kepuasan pasien Askes terhadap pelayanan instalasi rawat inap B di RSUP Prof. Dr. R. D. Kandou Manado [Tesis]. Manado: Universitas Sam Ratulangi; 2012.

9. Kambong M, Pangemanan JM, Kapantouw GHM. Hubungan antara pelayanan perawat dengan kepuasan pasien di Puskesmas Talawaan Kecamatan Talawaan Kabupaten Minahasa Utara. Jurnal Kesehatan Masyarakat Universitas Sam
Ratulangi. 2013;1:7.

10. Hendrik GL. Analisis pengaruh kualitas layanan terhadap kepuasan pasien pada Rumah Sakit Elim Kabupaten Toraja Utara [Skripsi]. Makassar: Universitas Hasanuddin; 2012.

11. Badri MA, Attia S, Ustadi AM. Healthcare quality and moderators of patient satisfaction: testing for causality. International Journal of Health Care Quality Assurance. 2008;22:4.

12. Mumu LJ, Kandou GD, Doda DV. Analisis faktor-faktor yang berhubungan dengan kepuasan pasien di Poliklinik Penyakit Dalam RSUP Prof. Dr. R. D. Kandou Manado [Tesis]. Manado: Universitas Sam Ratulangi; 2015.

13. Parasuraman A, Zeithaml VA, Berry LL. SERVQUAL: A multiple-item scale for measuring consumer perceptions of service quality. Journal of Retailing. 1988;64(1):12-40.

14. Calisir F, Gumussoy CA, Bayraktaroglu AE, Kaya B. Effects of service quality dimensions on customer satisfaction and return intention in different hospital types. Proceedings of the 2012 International Conference on Industrial Engineering and Operations Management. 2012; p. 518-22. 